\title{
Mathematical Models Arising in the Fractal Forest Gap via Local Fractional Calculus
}

\author{
Chun-Ying Long, ${ }^{1}$ Yang Zhao, ${ }^{2}$ and Hossein Jafari ${ }^{3,4}$ \\ ${ }^{1}$ School of Civil Engineering and Architecture, Nanchang University, Nanchang 330031, China \\ ${ }^{2}$ Electronic and Information Technology Department, Jiangmen Polytechnic, Jiangmen 529090, China \\ ${ }^{3}$ Department of Mathematics, Faculty of Mathematical Sciences, University of Mazandaran, Babolsar 47415-416, Iran \\ ${ }^{4}$ African Institute for Mathematical Sciences, Muizenberg 7945, South Africa \\ Correspondence should be addressed to Yang Zhao; zhaoyang19781023@gmail.com
}

Received 8 January 2014; Accepted 10 February 2014; Published 18 March 2014

Academic Editor: Carlo Cattani

Copyright ( 2014 Chun-Ying Long et al. This is an open access article distributed under the Creative Commons Attribution License, which permits unrestricted use, distribution, and reproduction in any medium, provided the original work is properly cited.

The forest new gap models via local fractional calculus are investigated. The JABOWA and FORSKA models are extended to deal with the growth of individual trees defined on Cantor sets. The local fractional growth equations with local fractional derivative and difference are discussed. Our results are first attempted to show the key roles for the nondifferentiable growth of individual trees.

\section{Introduction}

Fractals had been used to describe special problems in biology and ecology [1-4] because of the measure of nature objects underlying the geometry, replacing the complex realworld objects by describing the Euclidean ideas. Fractal dimension was applied to describe the measure of the complexity in biology and ecology. In forestry, the fractal geometry had been applied to estimate stand density, predict forest succession, and describe the form of trees [5-7]. The scaling of dynamics in hierarchical structure was investigated in [8-12]. The ecological resilience example from boreal forest was presented in the context [8]. The quantitative theory of forest structure was discussed [9]. The allometric scaling laws in biology were proposed in the works [10, 11]. Based upon the cross-scale analysis, the geometry and dynamics of ecosystems were considered and the structure ecosystems across scales in time and space were discussed in [12, 13]. Fractal forestry was modeled by using the scaling of the testing parameters for ecological complexity.

Forest gap model (JABOWA) developed by Botkin et al. [14-16] was the first simulation model for gap-phase replacement. It was applied to describe a forest as a mosaic of closed canopies and simulate forest dynamics based upon the establishment, growth, and death of individual trees [1720]. The JABOWA model in the form of the FORET model (called JABOWA-FORET) was further developed in [21-24]. The JABOWA model of the simulation of stand structure in a forest gap model was improved in [24] and the FORSKA [25] was proposed by Botkin et al. In [14-16], the ecological functions are continuous. In [10-13], the ecological functions were expressed across scales in time and space. However, as it is shown in Figure 1 the ecological functions distinguishing hierarchical size scales in nature, such as the measures of tree size and measure of soil fertility, are defined on Cantor sets. The above approaches do not deal with them.

Local fractional calculus theory [26-38] was applied to handle the nondifferentiable functions defined on Cantor sets. The heat-conduction, transport, Maxwell, diffusion, wave, Fokker-Planck, and the mechanical structure equations were usefully shown (see for more details [28-36] and the cited references therein). In order to simulate forest dynamics on the basis of the establishment, growth, and death of individual trees defined on Cantor sets, the aim of this paper is to present the forest new gap models for simulating the gapphase replacement by employing the local fractional calculus.

The paper has been organized as follows. In Section 2, we review the JABOWA and FORSKA models for the forest 


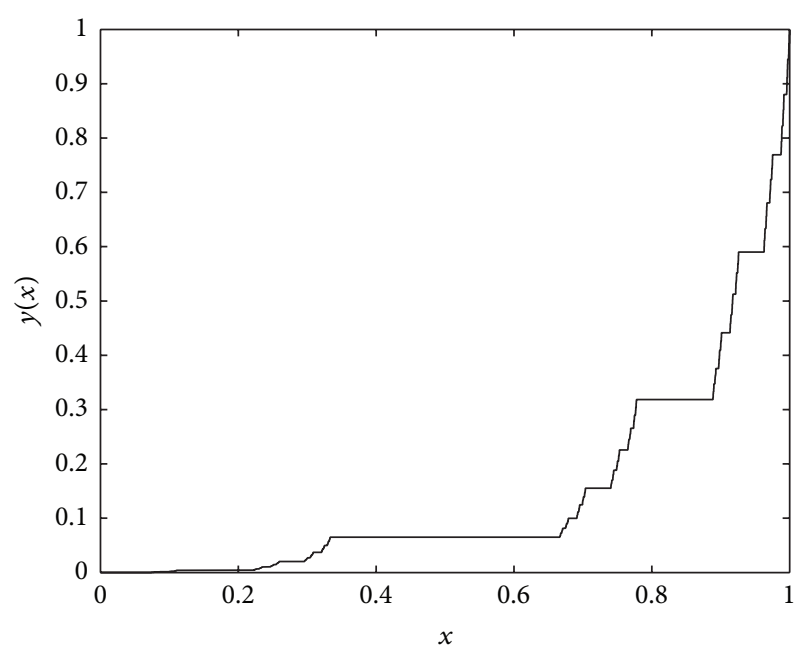

Figure 1: The ecological function $f(x)$ defined on Cantor set.

succession. In Section 3, we propose JABOWA and FORSKA models for the fractal forest succession. Finally, Section 4 is conclusions.

\section{Growth Models for Forest Gap}

In this section we will revise the JABOWA and FORSKA models.

2.1. The JABOWA Model. The growth equation with difference form is given by $[15,16,24,39]$

$$
\frac{\Delta D}{\Delta t}=G \cdot D \cdot \phi(D) \cdot \frac{1}{b(D)} \cdot f(e),
$$

where the function $D$ is diameter at breast height of the trees, the parameter $H$ is tree height, $G$ is a growth rate, the function $b(D)$ is a quantity encapsulating this allometric relationship, $f(e)$ is a quantity influencing the abiotic and biotic environment on tree growth, $\phi(D)=\left(1-D \cdot H /\left(D_{\max }\right.\right.$. $\left.H_{\max }\right)$ ), and $D_{\max }$ and $H_{\max }$ are the maximum measures of the tree dimensions.

The parameter $f(e)$ is simulated as follows [24]:

$$
f(e)=g_{1}(\mathrm{AL}) \cdot g_{2}(\mathrm{SBAR}) \cdot g_{3}(\mathrm{DD}),
$$

where $g_{1}(\mathrm{AL})$ is a quantity of available light, $g_{2}(\mathrm{SBAR})$ is a quantity of stand basal area, and $g_{2}$ (SBAR) is a quantity of the annual degree-day sum. It was referred to as Liebig's law of the minimum [24].

The allometric relationship with a parabolic form is written as follows $[24,40]$ :

$$
b(D)=b_{1}+b_{2} D+b_{3} D^{2}
$$

where $b_{1}, b_{2}$, and $b_{3}$ are parameters.

Leaf area index reads as follows [24]:

$$
\mathrm{LAI}=\mu D^{2}
$$

where $\mu=c / k$ with a species-specific parameter $c$ and the scale leaf weight per tree to the projected leaf area $k$.

In order to implement a new height-diameter relationship [40], the differential form of growth equation in the JABOWA model was suggested as follows [41]:

$$
\frac{d D}{d t}=G \cdot D \cdot \varphi(D)
$$

where the function has the following form:

$$
\varphi(D)=\frac{1-H / H_{\max }}{2 H_{\max }-b(-s D / b+2) e^{-D s / b}}
$$

with the parameter $b=H_{\max }-137$ and the initial slope value of the height diameter relationship $s$.

2.2. The FORSKA Model. The FORSKA model was developed for unmanaged natural forests and tree height had $H-D$ relationship with the FORSKA model given by $[24,25,39,41]$

$$
H=1.3+\left(H_{\max }-1.3\right) \cdot\left(1-e^{-s D /\left(H_{\max }-1.3\right)}\right),
$$

where the parameter $s$ is the initial slope value of the height diameter relationship at $D=0, H_{\max }$ is the maximum measure of the tree dimension, $D$ is diameter at breast height of the trees, and $H$ is tree height.

As it is known, the trees in the real forest do not follow the $H-D$ relationship. The growth equation with differential form can be written as follows [24, 25]:

$$
\frac{d H}{d D}=s \cdot f(H)
$$

where

$$
f(H)=\frac{H-1.3}{H_{\max }-1.3} .
$$

\section{The JABOWA and FORSKA Models for the Fractal Forest Succession}

In this section, based upon the local fractional calculus theory, we show the JABOWA and FORSKA models for the fractal forest succession. At first, we start with the local fractional derivative.

3.1. Local Fractional Derivative. We now give the local fractional calculus and the recent results.

If

$$
\left|f(x)-f\left(x_{0}\right)\right|<\varepsilon^{\alpha}
$$

with $\left|x-x_{0}\right|<\delta$, for $\varepsilon, \delta>0$ and $\varepsilon, \delta \in R$, then we denote [26-28]

$$
f(x) \in C_{\alpha}(a, b) .
$$

If $f(x) \in C_{\alpha}(a, b)$, then we have [26]

$$
\operatorname{dim}_{H}(F \cap(a, b))=\operatorname{dim}_{H}\left(C_{\alpha}(a, b)\right)=\alpha,
$$


where $C_{\alpha}(a, b)=\{f: f(x)$ is local fractional continuous, $x \in F \cap(a, b)\}$.

Let $f(x) \in C_{\alpha}(a, b)$. The local fractional derivative of $f(x)$ of order $\alpha$ at $x=x_{0}$ is defined as [26-34]

$$
f^{(\alpha)}\left(x_{0}\right)=\left.\frac{d^{\alpha} f(x)}{d x^{\alpha}}\right|_{x=x_{0}}=\lim _{x \rightarrow x_{0}} \frac{\Delta^{\alpha}\left(f(x)-f\left(x_{0}\right)\right)}{\left(x-x_{0}\right)^{\alpha}},
$$

where $\Delta^{\alpha}\left(f(x)-f\left(x_{0}\right)\right) \cong \Gamma(1+\alpha) \Delta\left(f(x)-f\left(x_{0}\right)\right)$.

For $0<\alpha \leq 1$, the increment of $f(x)$ can be written as follows $[26,27]$ :

$$
\Delta^{\alpha} f(x)=f^{(\alpha)}(x)(\Delta x)^{\alpha}+\lambda(\Delta x)^{\alpha},
$$

where $\Delta x$ is an increment of $x$ and $\lambda \rightarrow 0$ as $\Delta x \rightarrow 0$.

For $0<\alpha \leq 1$, the $\alpha$-local fractional differential of $f(x)$ reads as $[26,27]$

$$
d^{\alpha} f=f^{(\alpha)}(x)(d x)^{\alpha} .
$$

From (14), we have approximate formula in the form

$$
\Delta^{\alpha} f(x) \cong \Gamma(1+\alpha) \Delta\left(f(x)-f\left(x_{0}\right)\right) .
$$

Let $f(x) \in C_{\alpha}(a, b)$. The local fractional integral of $f(x)$ of order $\alpha$ is given by [26-31]

$$
\begin{aligned}
{ }_{a} I_{b}^{(\alpha)} f(x) & =\frac{1}{\Gamma(1+\alpha)} \int_{a}^{b} f(t)(d t)^{\alpha} \\
& =\frac{1}{\Gamma(1+\alpha)} \lim _{\Delta t \rightarrow 0} \sum_{j=0}^{j=N-1} f\left(t_{j}\right)\left(\Delta t_{j}\right)^{\alpha},
\end{aligned}
$$

where $\Delta t_{j}=t_{j+1}-t_{j}, \Delta t=\max \left\{\Delta t_{1}, \Delta t_{2}, \Delta t_{j}, \ldots\right\}$, and $\left[t_{j}, t_{j+1}\right], j=0, \ldots, N-1, t_{0}=a, t_{N}=b$, is a partition of the interval $[a, b]$.

The $\alpha$-dimensional Hausdorff measure $H_{\alpha}$ is calculated by [26]

$$
H_{\alpha}(F \cap(0, x))={ }_{0} I_{x}^{(\alpha)} 1=\frac{x^{\alpha}}{\Gamma(1+\alpha)} .
$$

3.2. The Local Fractional JABOWA Models (LFJABOWA). Here, we structure the LFJABOWA models via local fractional derivative and difference.

From (5), when

$$
G \cdot \varphi(D)=\lambda_{0} D^{\beta-1},
$$

the Enquist growth model in JABOWA model reads as [11, 42]

$$
\frac{d D}{d t}=\lambda_{0} D^{\beta}
$$

where $D$ is the diameter at breast height, $\lambda_{0}$ is the scaling coefficient, and $\beta$ is the fractal dimension.

Making use of the fractional complex transform [29] and (20), the growth equation in the JABOWA model with local fractional derivative (LFJABOWA) is suggested by

$$
\frac{d^{\alpha} D}{d t^{\alpha}}=\lambda_{0} D^{\beta}
$$

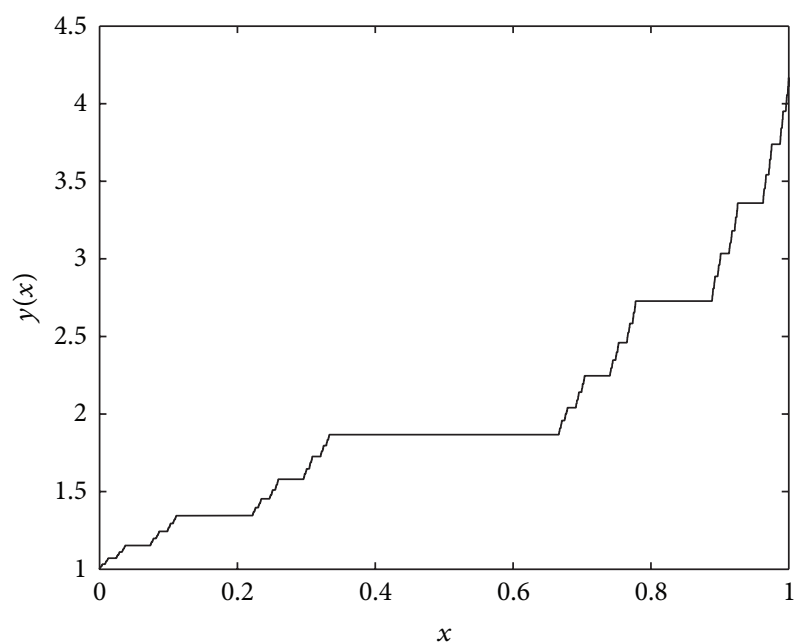

FIGURE 2: The graph of (22) with parameters $\beta=1, \lambda_{0}=1$, and $t_{0}=0$.

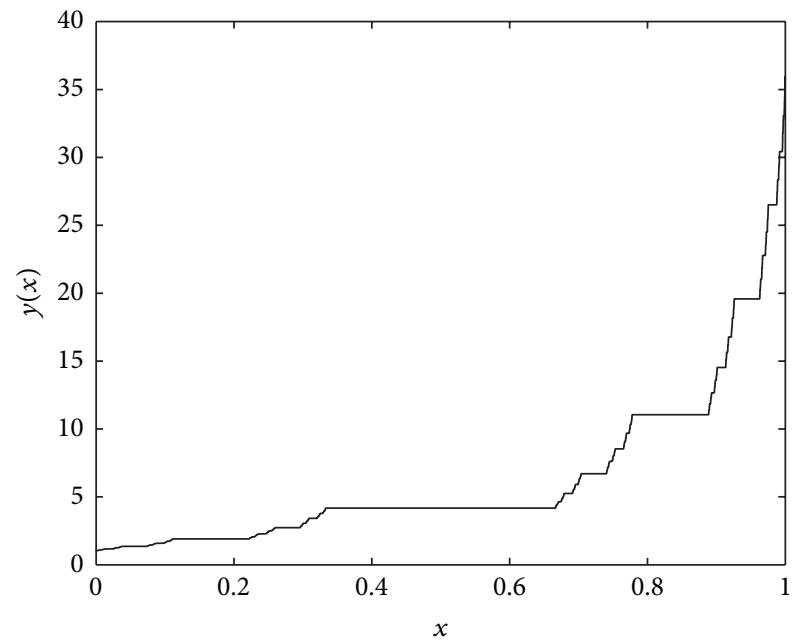

FIGURE 3: The graph of (22) with parameters $\beta=1, \lambda_{0}=2$, and $t_{0}=0$.

where $D$ is the diameter at breast height, $\lambda_{0}$ is the scaling coefficient, and $\alpha$ and $\beta$ are the fractal dimensions. In order to illustrate the difference from the works presented in [42], we consider the following case: when $\beta=1,(21)$ can be integrated to give

$$
D(t)=E_{\alpha}\left(\lambda_{0} t^{\alpha}\right)-E_{\alpha}\left(\lambda_{0} t_{0}^{\alpha}\right) .
$$

For the parameters $\beta=1, t=0$, the solutions of (21) with different values $\lambda_{0}=1, \lambda_{0}=2, \lambda_{0}=3$, and $\lambda_{0}=4$ are, respectively, shown in Figures 2, 3, 4, and 5.

Using the fractional complex transform, (5) becomes into

$$
\frac{d^{\alpha} D}{d t^{\alpha}}=G \cdot D \cdot \varphi(D)
$$

Comparing (22) and (23), we have

$$
\frac{d^{\alpha} D}{d t^{\alpha}}=\psi(t, D)
$$




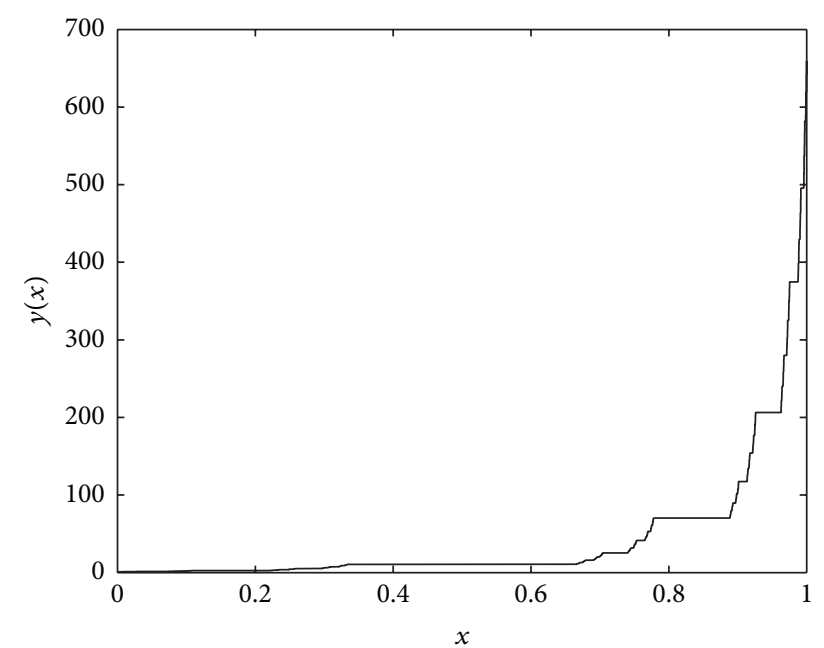

FIGURE 4: The graph of (22) with parameters $\beta=1, \lambda_{0}=3$, and $t_{0}=0$.

where

$$
\psi(t, D)=G \cdot D \cdot \varphi(D)
$$

or

$$
\psi(t, D)=\lambda_{0} D^{\beta}
$$

From (25) and (26), we could get

$$
\begin{gathered}
\varphi(D)=D^{\beta-1}, \\
\lambda_{0}=G .
\end{gathered}
$$

Hence, the local fractional JABOWA model (LFJABOWA) reads as follows:

$$
\frac{d^{\alpha} D}{d t^{\alpha}}=\psi(t, D)
$$

where $\psi(t, D)$ is a nondifferentiable function and $D$ is the diameter at breast height.

In view of (16), from (29) we give the difference form of local fractional JABOWA model (LFJABOWA) in the following form:

$$
\frac{\Delta^{\alpha} D}{(\Delta t)^{\alpha}}=\psi(t, D)
$$

where $D$ is the diameter at breast height and $\Delta^{\alpha} D(t) \cong \Gamma(1+$ $\alpha) \Delta\left(D(t)-D\left(t_{0}\right)\right)$.

When the fractal dimension $\alpha$ is equal to 1 , we get the generalized form of (1); namely,

$$
\frac{\Delta D}{\Delta t}=\psi(t, D),
$$

where

$$
\psi(t, D)=G \cdot D \cdot \phi(D) \cdot \frac{1}{b(D)} \cdot f(e)
$$

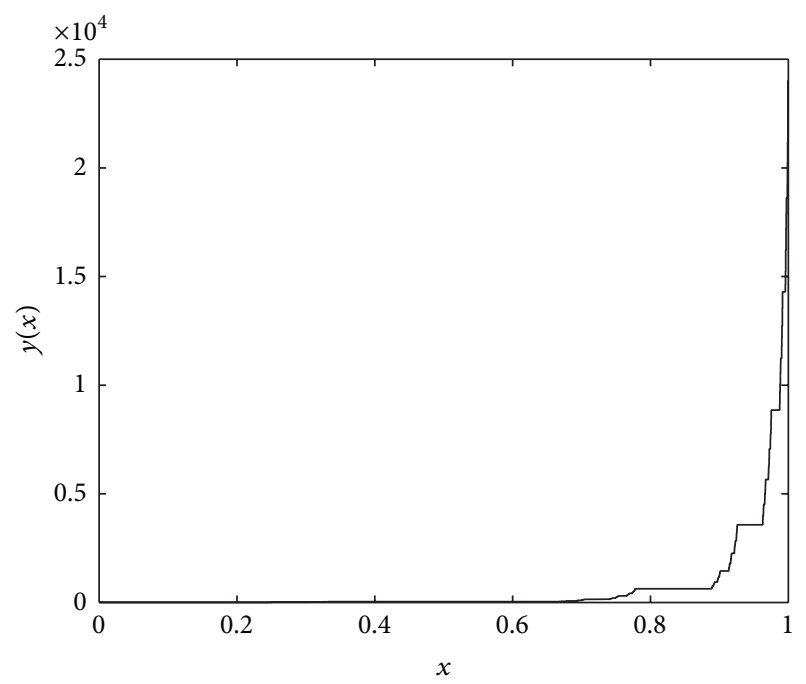

Figure 5: The graph of (22) with parameters $\beta=1, \lambda_{0}=4$, and $t_{0}=0$.

3.3. The Local Fractional FORSKA Models (LFFORSKA). Here, we present the LFFORSKA models via local fractional derivative and difference.

The tree height $H$ is the nondifferentiable function; namely,

$$
\left|H(D)-H\left(D_{0}\right)\right|<\varsigma^{\alpha},
$$

where for $\varsigma, \vartheta>0 \varsigma, \vartheta \in R$, and $\left|D-D_{0}\right|<\vartheta$.

Following the fractional complex transform [29], from (8) we have the local fractional growth equation in the following form:

$$
\frac{d^{\alpha} H}{d D^{\alpha}}=s \cdot f(H),
$$

where $f(H)$ is a local fractional continuous function, $H$ is the tree height, and $s$ is a parameter.

Therefore, the generalized form of (34) is suggested as follows:

$$
\frac{d^{\alpha} H}{d D^{\alpha}}=\chi(D, H)
$$

where $D$ is the diameter at breast height and $H$ is the tree height. In view of (16), (35) can be rewritten as follows:

$$
\frac{\Delta^{\alpha} H}{(\Delta D)^{\alpha}}=\chi(D, H),
$$

where

$$
\begin{gathered}
\left|D-D_{0}\right|<\vartheta, \\
\left|H(D)-H\left(D_{0}\right)\right|<\varsigma^{\alpha} .
\end{gathered}
$$

The expression (36) is the difference form of local fractional FORSKA model (LFFORSKA). 


\section{Conclusions}

In this work we investigated the local fractional models for the fractal forest succession. Based on the local fractional operators, we suggested the differential and difference forms of the local fractional JABOWA and FORSKA models. The nondifferentiable growths of individual trees were discussed. It is a good start for solving the rhetorical models for the fractal forest succession in the mathematical analysis.

\section{Conflict of Interests}

The authors declare that they have no conflict of interests regarding the publication of this paper.

\section{Acknowledgment}

This work is supported by the Science and Technology Commission Planning Project of Jiangxi Province (no. 20122BBG70078).

\section{References}

[1] A. Fielding, "Applications of fractal geometry to biology," Computer Applications in the Biosciences, vol. 8, no. 4, pp. 359366, 1992.

[2] B. L. Li, "Fractal geometry applications in description and analysis of patch patterns and patch dynamics," Ecological Modelling, vol. 132, no. 1, pp. 33-50, 2000.

[3] G. Sugihara and R. M. May, "Applications of fractals in ecology," Trends in Ecology \& Evolution, vol. 5, no. 3, pp. 79-86, 1990.

[4] J. H. Brown, V. K. Gupta, B. L. Li, B. T. Milne, C. Restrepo, and G. B. West, "The fractal nature of nature: power laws, ecological complexity and biodiversity," Philosophical Transactions of the Royal Society of London B, vol. 357, no. 1421, pp. 619-626, 2002.

[5] N. D. Lorimer, R. G. Haight, and R. A. Leary, The Fractal Forest: Fractal Geometry and Applications in Forest Science, North Central Forest Experiment Station, Berkeley, Calif, USA, 1994.

[6] B. Zeide, "Fractal geometry in forestry applications," Forest Ecology and Management, vol. 46, no. 3, pp. 179-188, 1991.

[7] B. Zeide, "Analysis of the $3 / 2$ power law of self-thinning," Forest Science, vol. 33, no. 2, pp. 517-537, 1987.

[8] G. D. Peterson, "Scaling ecological dynamics: self-organization, hierarchical structure, and ecological resilience," Climatic Change, vol. 44, no. 3, pp. 291-309, 2000.

[9] G. B. West, B. J. Enquist, and J. H. Brown, "A general quantitative theory of forest structure and dynamics," Proceedings of the National Academy of Sciences, vol. 106, no. 17, pp. 7040-7045, 2009.

[10] G. B. West, J. H. Brown, and B. J. Enquist, "A general model for the origin of allometric scaling laws in biology," Science, vol. 276, no. 5309, pp. 122-126, 1997.

[11] B. J. Enquist, G. B. West, E. L. Charnov, and J. H. Brown, "Allometric scaling of production and life-history variation in vascular plants," Nature, vol. 401, no. 6756, pp. 907-911, 1999.

[12] C. S. Holling, "Cross-scale morphology, geometry, and dynamics of ecosystems," Ecological Monographs, vol. 62, no. 4, pp. 447-502, 1992.
[13] G. Peterson, C. R. Allen, and C. S. Holling, "Ecological resilience, biodiversity, and scale," Ecosystems, vol. 1, no. 1, pp. 6-18, 1998.

[14] D. B. Botkin, J. F. Janak, and J. R. Wallis, "Rationale, limitations, and assumptions of a northeastern forest growth simulator," IBM Journal of Research and Development, vol. 16, no. 2, pp. 101$116,1972$.

[15] D. B. Botkin, J. F. Janak, and J. R. Wallis, "Some ecological consequences of a computer model of forest growth," The Journal of Ecology, vol. 60, no. 3, pp. 849-872, 1972.

[16] D. B. Botkin, Forest Dynamics: An Ecological Model, Oxford University Press, New York, NY, USA, 1993.

[17] G. L. Perry and N. J. Enright, "Spatial modelling of vegetation change in dynamic landscapes: a review of methods and applications," Progress in Physical Geography, vol. 30, no. 1, pp. 47-72, 2006.

[18] R. Chen and R. R. Twilley, "A gap dynamic model of mangrove forest development along gradients of soil salinity and nutrient resources," Journal of Ecology, vol. 86, no. 1, pp. 37-51, 1998.

[19] R. W. Hall, “JABOWA revealed-finally," Ecology, vol. 75, no. 3, p. 859, 1994.

[20] M. I. Ashraf, C. P. A. Bourque, D. A. MacLean, T. Erdle, and F. R. Meng, "Using JABOWA-3 for forest growth and yield predictions under diverse forest conditions of Nova Scotia, Canada," The Forestry Chronicle, vol. 88, no. 6, pp. 708-721, 2012.

[21] H. H. Shugart and I. R. Noble, "A computer model of succession and fire response of the high-altitude Eucalyptus forest of the Brindabella Range, Australian Capital Territory," Australian Journal of Ecology, vol. 6, no. 2, pp. 149-164, 1981.

[22] H. H. Shugart and D. C. West, "Development of an Appalachian deciduous forest succession model and its application to assessment of the impact of the chestnut blight," Journal of Environmental Management, vol. 5, pp. 161-179, 1977.

[23] H. H. Shugart, A Theory of Forest Dynamics. The Ecological Implications of Forest Succession Models, Springer, New York, NY, USA, 1984.

[24] H. Bugmann, "A review of forest gap models," Climatic Change, vol. 51, no. 3-4, pp. 259-305, 2001.

[25] M. Lindner, R. Sievänen, and H. Pretzsch, "Improving the simulation of stand structure in a forest gap model," Forest Ecology and Management, vol. 95, no. 2, pp. 183-195, 1997.

[26] X.-J. Yang, Advanced Local Fractional Calculus and Its Applications, World Science, New York, NY, USA, 2012.

[27] X. J. Yang, Local Fractional Functional Analysis and Its Applications, Asian Academic, Hong Kong, China, 2011.

[28] X. J. Yang and D. Baleanu, "Fractal heat conduction problem solved by local fractional variation iteration method," Thermal Science, vol. 17, no. 2, pp. 625-628, 2013.

[29] X. J. Yang, D. Baleanu, and J. H. He, “Transport equations in fractal porous media within fractional complex transform method," Proceedings of the Romanian Academy A, vol. 14, no. 4, pp. 287-292, 2013.

[30] C. F. Liu, S. S. Kong, and S. J. Yuan, "Reconstructive schemes for variational iteration method within Yang-Laplace transform with application to fractal heat conduction problem," Thermal Science, vol. 17, no. 3, pp. 715-721, 2013.

[31] A. M. Yang, Y. Z. Zhang, and Y. Long, "The Yang-Fourier transforms to heat-conduction in a semi-infinite fractal bar," Thermal Science, vol. 17, no. 3, pp. 707-713, 2013.

[32] Y. Zhao, D. Baleanu, C. Cattani, D. F. Cheng, and X.-J. Yang, "Maxwell's equations on Cantor Sets: a local fractional 
approach," Advances in High Energy Physics, vol. 2013, Article ID 686371, 6 pages, 2013.

[33] X. J. Yang, D. Baleanu, and W. P. Zhong, "Approximate solutions for diffusion equations on Cantor space-time," Proceedings of the Romanian Academy A, vol. 14, no. 2, pp. 127-133, 2013.

[34] X.-J. Yang, H. M. Srivastava, J. H. He, and D. Baleanu, "Cantortype cylindrical-coordinate method for differential equations with local fractional derivatives," Physics Letters A, vol. 377, no. 28-30, pp. 1696-1700, 2013.

[35] K. M. Kolwankar and A. D. Gangal, "Local fractional FokkerPlanck equation," Physical Review Letters, vol. 80, no. 2, pp. 214217, 1998.

[36] A. Carpinteri, B. Chiaia, and P. Cornetti, "Static-kinematic duality and the principle of virtual work in the mechanics of fractal media," Computer Methods in Applied Mechanics and Engineering, vol. 191, no. 1-2, pp. 3-19, 2001.

[37] F. Ben Adda and J. Cresson, "About non-differentiable functions," Journal of Mathematical Analysis and Applications, vol. 263, no. 2, pp. 721-737, 2001.

[38] A. Babakhani and V. Daftardar-Gejji, "On calculus of local fractional derivatives," Journal of Mathematical Analysis and Applications, vol. 270, no. 1, pp. 66-79, 2002.

[39] H. K. Bugmann, X. Yan, M. T. Sykes et al., "A comparison of forest gap models: model structure and behaviour," Climatic Change, vol. 34, no. 2, pp. 289-313, 1996.

[40] A. D. Moore, "On the maximum growth equation used in forest gap simulation models," Ecological Modelling, vol. 45, no. 1, pp. 63-67, 1989.

[41] A. C. Risch, C. Heiri, and H. Bugmann, "Simulating structural forest patterns with a forest gap model: a model evaluation," Ecological Modelling, vol. 181, no. 2-3, pp. 161-172, 2005.

[42] D. A. Coomes and R. B. Allen, "Effects of size, competition and altitude on tree growth," Journal of Ecology, vol. 95, no. 5, pp. 1084-1097, 2007. 


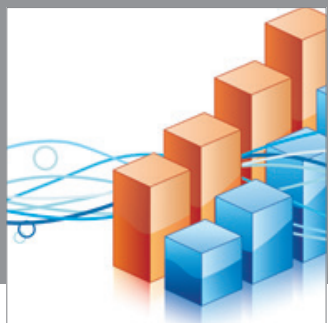

Advances in

Operations Research

mansans

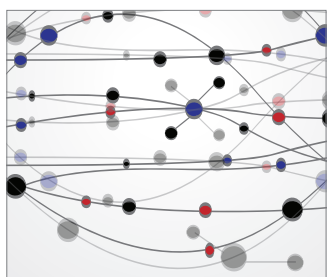

The Scientific World Journal
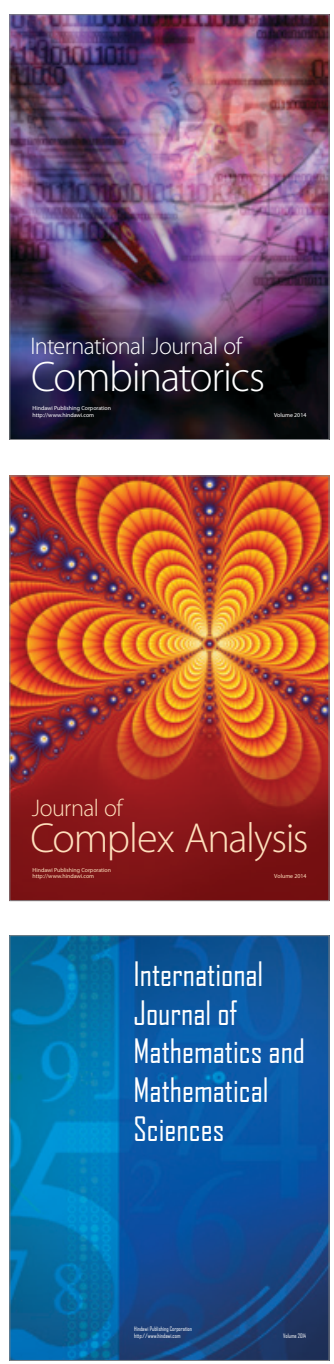
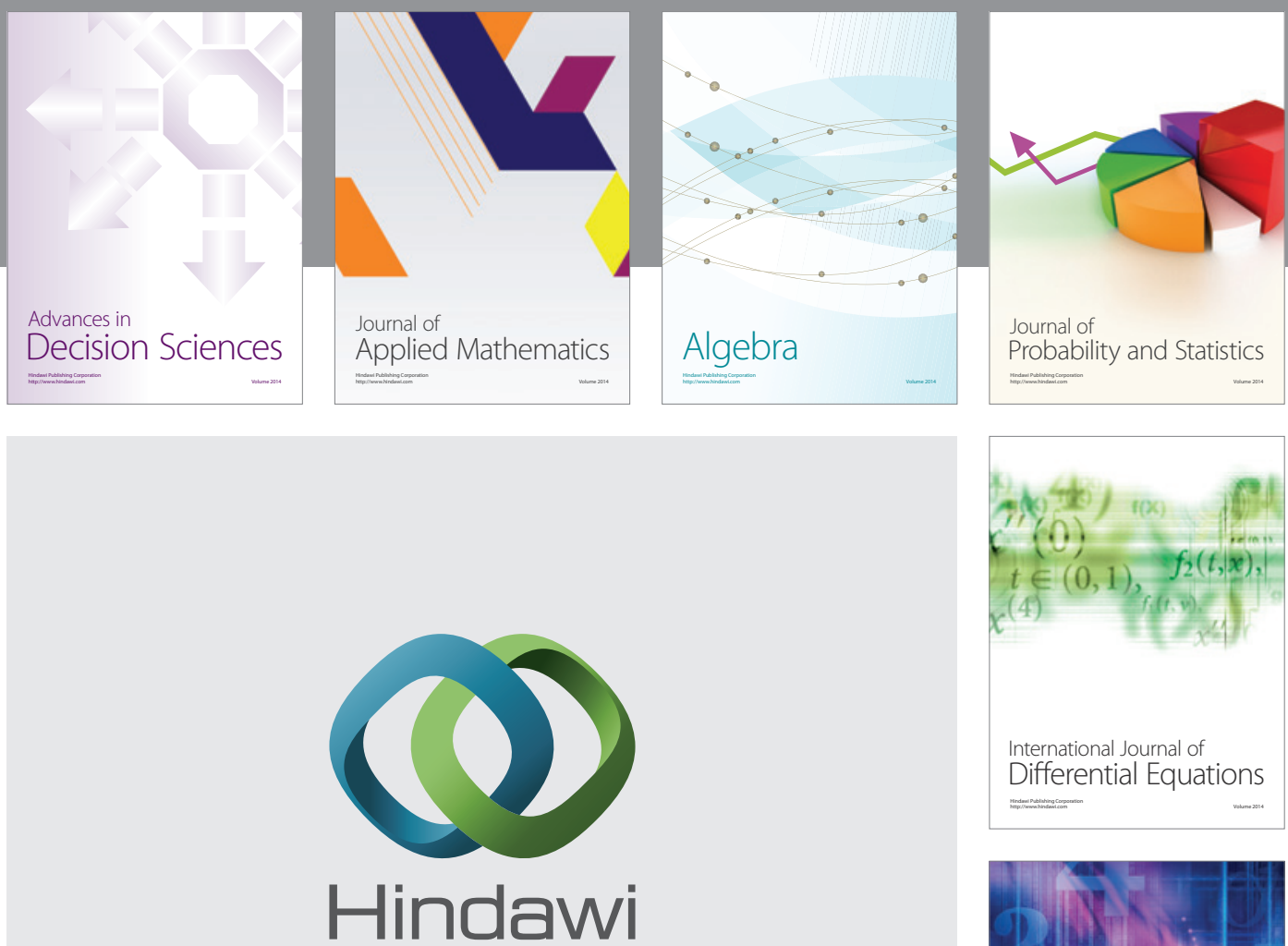

Submit your manuscripts at http://www.hindawi.com
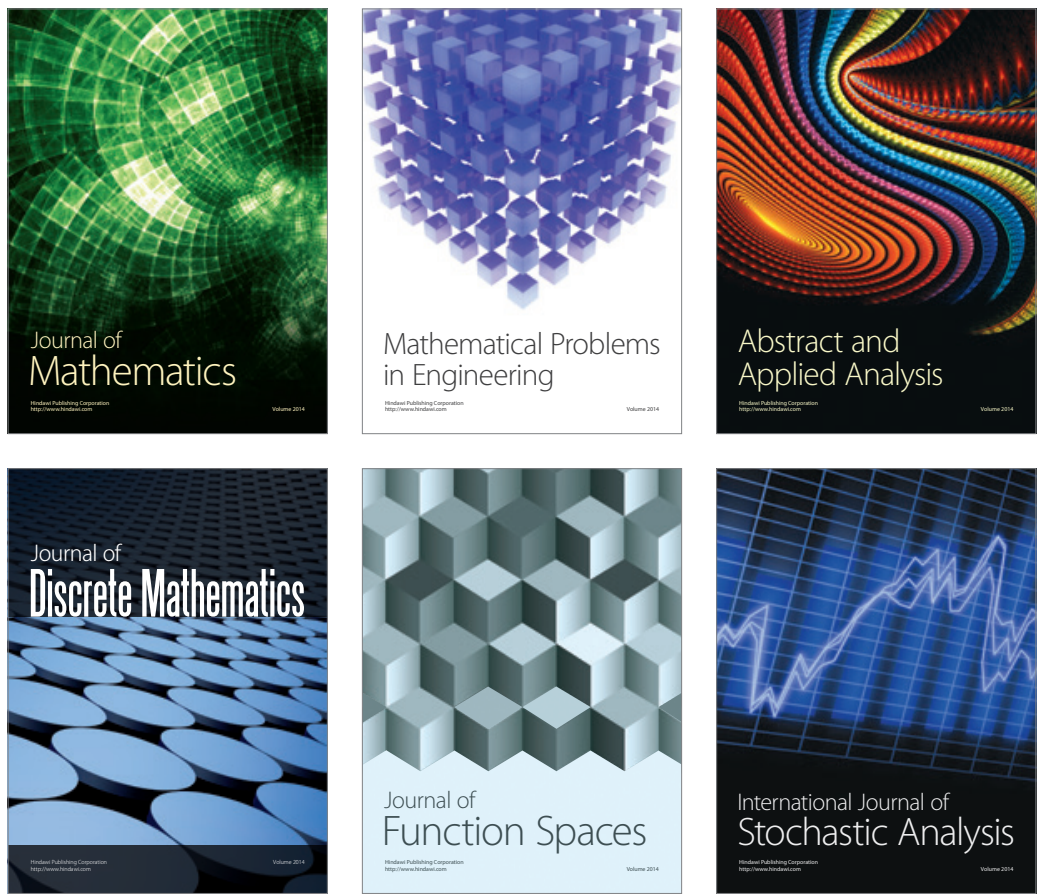

Journal of

Function Spaces

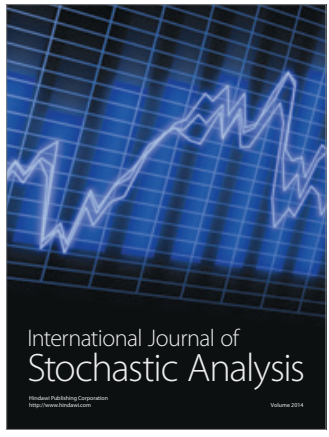

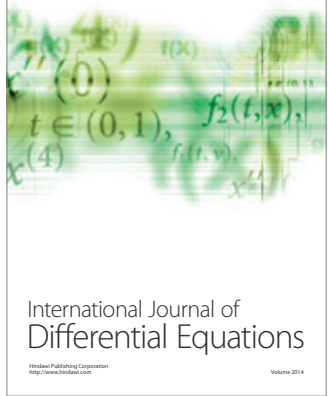
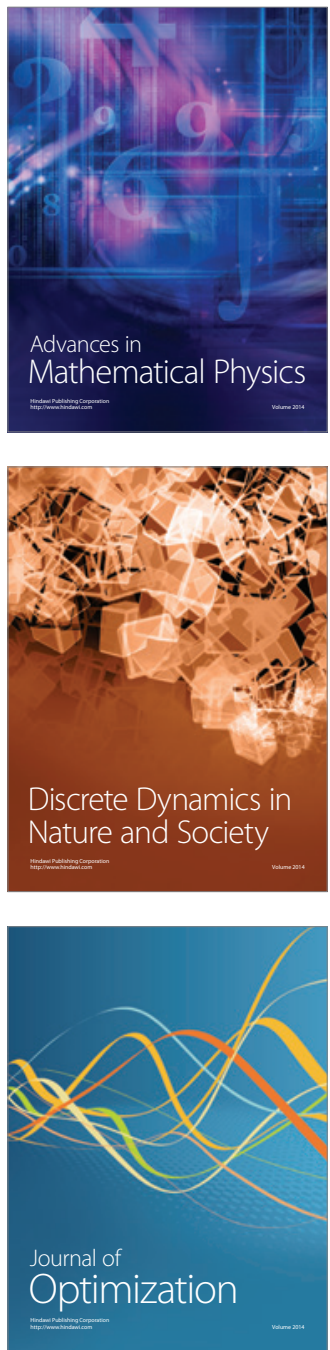